\title{
The Effectiveness of Human Validation Process Model Training on Couples' Marital Satisfaction
}

Loghman Ebrahimi*

Department of Psychology, University of Zanjan, Zanjan, Iran

\begin{abstract}
Current survey has been accomplished in Zanjan City to evaluate the impact of Human Validitation Process Model in the increase of Marital Satisfaction level. This research was carried out choosing semi-experimental method (pre-test, post-test, case control study). Statistical society was selected among the volunteer couples referred to consultation centre of Welfare Department of Zanjan City following the relevant recall of researcher. Among a total of 72 people (36 couples), 60 people were randomly selected as a sample group (based on the methodology of this survey). They were placed in two individual groups. 15 experimental couples and 15 case control couples. There was also a drop of 4 people ( 2 couples per each group), up the end of determined time period. Pretest Enrich Marital Satisfaction Scale (47 Questions) conducted in both groups (case control and experimental group respectively). Then, therapeutic instructions were trained in eight sessions to each couple according to of Human Validitation Process Model. Simultaneously, control case group was placed in waiting list to receive counseling services. After termination all the sessions, both groups undertook post-test questionnaire. Descriptive statistics including (Frequency, mean and variance) and inferential statistics (to assess student's t-test) were applied to analyze dependent and independent samples. Findings suggested that Human Validitation Process Model significantly increased Marital Satisfaction level $(P<0.001)$. In addition, the comparative analysis identified a significant difference between men and women in terms of impact of marital satisfaction level following the application this model. So, the author concluded that the impact of this model was more than in women comparing with men $\mathrm{P}<0.05$. human validation process model training increased marital satisfaction.
\end{abstract}

Keywords: Human validitation process model; Marital satisfaction

\section{Introduction}

There is much evidence proving that there are serious problems among couples in making love and as well as keeping it. In fact, the problem of dissatisfaction in marital life constitutes the main problem for which the couples decide to refer to counseling centers. Since marital satisfaction is largely associated with solving conflicts which for sure occur in the changing marital life, the necessity of using some solutions for these conflicts which would lead to more and better satisfaction seems quite important and clear. The short term effect of marital satisfaction is couples playing their roles quietly well in regard to each other and also to their children. This would specify the family health and make appropriate grounds for the blooming of their own talents as well as their children's. The long term marital satisfaction is defined as the entrance of healthy individuals from family into society which will reduce the costs concerning social disorders and incompatibilities and also will result in cultural, social, political and religious growth [1].

There are various definitions for marital satisfaction. According to Ellis [2] one of the best definitions is as follows: the wife and husband have raw feelings of satisfaction and pleasure in their all mutual relationships. Therefore, marital satisfaction is in fact a positive and pleasing vision by couples in every aspect of their marital life. Also, there are different factors which bring about marital satisfaction. Various studies show that the factors regarding individual's internal growth including characteristic features, feedbacks, beliefs, values and expectations as well as those related to individual's intra growth including love, intimacy, commitment, passions and sexual relationship, behavioral patterns, family and social issues also affect the degree of marital satisfaction [3]. Also Mollania [4] points to different effects of these factors on the degree of marital satisfaction from a couple to another and from a culture to another culture.

Being aware of this fact that some marital patterns and relationships between couples are in nature those processes which would guide them to separation, and also being aware of the way they can be changed and rebuilt, will help the couples to improve their relationships. All couples experience some levels of incompatibilities, lack of awareness or inability of couples to settle them would reduce the stability of relationships and increase separations [5] translated by Firouzbakht. Studies show how deficient and imperfect relations would affect marital satisfaction. In this regard, it have shown that when the communication method and interactional patterns between two individuals are not alike, the chance of dissatisfaction increases. Also, Moradi [6] showed that marital communication skill trainings will increase marital satisfaction among couples. If people obtain self-esteem, self-worth and then be able to make intimate relationships in family structure, they will perform positive and effective behaviors inside the family as well. Positive marital behaviors, could serve as an important information source of advice and solution for marital problems. Remedial and counseling intervenes of parents in order to improve personal relations and quality of marital satisfaction may fall useful for both couples and the behaviors of their children. The rational reasons behind studying the details of marital satisfaction are as follows: perceiving its major role in the family and individual health [7], its importance for the society so

*Corresponding author: Loghman Ebrahimi, Assistant Professor, Department of Psychology, University of Zanjan, Iran, Tel: +98 (0) 243305 4478; Fax: +98 (0) 24 3228 320; E-mail: L.ebrahimi@znu.ac.ir

Received February 15, 2017; Accepted February 24, 2018; Published March 01,2018

Citation: Ebrahimi L (2018) The Effectiveness of Human Validation Process Model Training on Couples' Marital Satisfaction. J Ment Disord Treat 4: 155. doi:10.4172/2471-271X.1000155

Copyright: @ 2018 Ebrahimi L. This is an open-access article distributed under the terms of the Creative Commons Attribution License, which permits unrestricted use, distribution, and reproduction in any medium, provided the original author and source are credited. 
that successful marriage takes place, giving up offence [8] and the need for developing experimental intervenes for couples in order to prevent or reduce marital stress and divorce [9].

Now a days, lots of various theoretical visions with different approaches are at work to settle marital conflicts and restore the unhealthy communication patterns and therefore improve marital satisfaction of couples. The pattern based on human validation can be referred to as an experimental approach to family issues. Therefore, since on one hand, one of the reasons for marital conflicts, marital dissatisfaction and finally divorce is couples' lack of communication and problem-solving needed skills and their lack of necessary abilities to make a safe, calm and intimate atmosphere, and on the other, lots of desired targets in the pattern based on satir's process of human validation like provoking feelings, specifying communication patterns in family, improving self-esteem and self-worth and human growth as a whole, compatible to a systematic vision to family, will be probably consistent with a lot of communication and emotional needs of couples, there is a need for practical researches to be done in order to find strategies to promote ill-working communication skills between couples and reduce family conflicts. In this regard, the pattern based on human validation as a part of experimental approach of family therapy is one of those approaches which pays much attention to communication and message delivery within families and present practical strategies and experiences to improve family potencies and the interactions within it. Experimental family therapy focuses on feelings and conflicts. It views awareness and feeling expression as tools for personal and family satisfaction [10]. According to this approach, families are consisted of individuals, and in order to change the family system, the individuals, as a part, should change their behavior [11]. Parsons and Alexander [12] could improve the communication patterns of families under treatment by using family therapy and taking advantage of behavior change strategies. There are a lot of researches proving that a large number of couples suffer from ill-communication patterns before making satisfactory marital relations. Research findings believe that dissatisfied and distracted couples fail to manage conflicts and solve issues and therefore make hard efforts to restore their communication actions. According to Christensen and Shenk [13] if a couple is not able to keep a mutual approach to constructively solve their inevitable differences, the conflict between them will grow. A decrease in the frequency of negative exchanges and an increase in the frequency of positive exchanges while describing conflicts and communication issues in a constructive way can be counted as the target of marital intervening programs [14] Pan [15] and quoted by Dadash et al. [16] applied the satir's family therapy approach in their research and showed its effectiveness in personal and self-esteem growth as well as an improvement in family performance. The results of this research showed that the quality of mother-daughter relationship was improved after applying family restoration.

According to above-mentioned issues, a need for carrying out the present research in order to improve couples' relationships and increase the amount of marital satisfaction is felt more than before. The results of the present research, will provide counselors and psychotherapists, especially family therapists, with a clear and applicable perspective on one hand, and on the other, will serve as a practical and experimental guidance to make self-esteem, increase self-worth of family members, clarify and rectify inconsistencies in family massage delivery and their communication patterns and in general human growth, and consequently decrease marital conflicts and enhance marital satisfaction. Furthermore, the results of the study could constitute theoretical and practical bases for reducing marital conflicts, improving communication patterns, and pre and post marriage trainings in order to prevent marital conflicts, which can be used in various educational and therapeutic institutes like counseling centers in universities, welfare organizations, clinics and problem-solving councils. Hence, conducting research on the field of effectiveness of this therapy method on increasing marital satisfaction seems necessary. In the present study efforts have been made to investigate the effectiveness of the training based on the pattern of human validation process on marital satisfaction.

\section{Method}

The present study is a quasi-experimental one which has been carried out with a pre-test and post-test design and a control group. The statistical population includes all the couples who, according to a recall made by the researcher, referred to welfare counseling center of Zanjan Province in 2017 in order to solve and improve their marital problems and relationships. The research sample consisted of 30 couples of Zanjan who accepted the recall. After determining and homogenizing the control and experimental groups, the researcher began to teach the pattern of human validation process to the experimental group in a two-month period, consisting of eight sessions of one hour and a half which were held weekly. The control group was held in a waiting status. Independent variables were marriage length, number of children, education. Marital satisfaction was controlled as the dependant variable.

In the present study, Enrich's marital satisfaction questionnaire was used to measure the marital satisfaction of couples. The questionnaire was designed by Olson et al. [17] and its aim was to measure the strong and weak points in marital relationships and to enrich them [17-19]. The questionnaire was in two formats: one contained 115 questions and the other 125 questions containing 5-item multiple choice questions (from extremely high to extremely low) which was consisted of 12 subscales: ideal perversion, marital satisfaction, personality issues, communication, conflict solving, financial management, leisure activities, sexual relationship, children raising, family and friends, egalitarian roles, religious positioning. The main format would make the subjects tired because of its large amount of questions. Soleimanian [19] in a research "investigating the effect of irrational thinking on marital dissatisfaction" prepared a shortened form of the questionnaire with 47 questions which was used in the present study. The Enrich's questionnaire has a validity of 1 and a high reliability of 2. The Chronbach's alpha is reported as 0.92 by Olson [17] 0.94 by Mahdavian and 0.93 by Soleimanian [19]. Rasooli [20] has measured the validity coefficient of the questionnaire through Chronbach's alpha. All the subscales of this questionnaire differentiated satisfied and unsatisfied couples which is a proof for the appropriate reliability of the questionnaire [21]. The content validity of the questionnaire has been affirmed by five psychological professors and family counsel specialists [22]. In the questionnaire, 5 items were designed for each sentence as follows: highly agree, agree, neither agree nor disagree, disagree, highly disagree. The scoring was respectively as $1,2,3,4,5$ for the mentioned items. The maximum score in the questionnaire was 235 . The higher a score was, the more marital satisfaction existed. Scores above 70 implied high marital satisfaction among couples and those below 30 indicated high marital dissatisfaction among them.

Selected couples were asked to refer to welfare counseling center of Zanjan Province in a pre-determined time. Enrich's marital satisfaction test was carried out separately for each couple. After conducting pre-test on both groups (control and experimental), with the active 
Citation: Ebrahimi L (2018) The Effectiveness of Human Validation Process Model Training on Couples' Marital Satisfaction. J Ment Disord Treat 4: 155. doi:10.4172/2471-271X.1000155

Page 3 of 5

participation of couples, certain days were determined according to their possible timetable. There were 8 training sessions, once a week for each couple which lasted from 90 to 120 minute (Table 1).

\section{Results}

Identifying the effect of training based on human validation pattern. In order to identify the effect of training based on human validation pattern in the experimental group, first the score obtained from marital satisfaction pre-test in both control and experimental group were compared. The satisfaction pre-test was administered to both groups and the obtained results for a whole number of 52 individuals in experimental and control group (as for the experimental group, the mean of pre-test scores was calculated as 98.88 , standard deviation as 19.71 and standard error was calculated as 3.87 . for the control group

\begin{tabular}{|c|c|c|c|c|c|}
\hline Session & Title & Theoretical base & Methodology & Practice & Assignment \\
\hline 1 & $\begin{array}{l}\text { Greeting and getting } \\
\text { familiar (trust- } \\
\text { making and joining } \\
\text { to family members) }\end{array}$ & $\begin{array}{l}\text { Pattern based on } \\
\text { human validation } \\
\text { process }\end{array}$ & $\begin{array}{l}\text { Introducing family members, trust-making between } \\
\text { individual and the family, determining evaluation } \\
\text { and therapeutic plans, sensitizing and attracting } \\
\text { family's attention to the general content of } \\
\text { sessions, making sense of the need for following } \\
\text { discussions in order to continue the sessions and } \\
\text { regular participation of members. Describing rules } \\
\text { and targets of the group, and then going over } \\
\text { recommendations, categorizing and leading them } \\
\text { through the plan, providing a daily report notepad, } \\
\text { sharing members' experience }\end{array}$ & $\begin{array}{l}\text { Doing meditation practices based on } \\
\text { human validation process }\end{array}$ & $\begin{array}{l}\text { Describing and recording } \\
\text { events in the daily report } \\
\text { notepad, determining } \\
\text { and recording the way } \\
\text { of interaction with and } \\
\text { reaction to them }\end{array}$ \\
\hline 2 & $\begin{array}{l}\text { Investigating } \\
\text { childhood security } \\
\text { and the effect of } \\
\text { family interaction } \\
\text { on family members' } \\
\text { role formation. }\end{array}$ & $\begin{array}{l}\text { Agitating and } \\
\text { facilitating } \\
\text { awareness } \\
\text { based on human } \\
\text { validation pattern }\end{array}$ & $\begin{array}{l}\text { Checking previous assignments, family members' } \\
\text { role playing (sculpturing), sharing members' } \\
\text { experiences, investigating each member's } \\
\text { sculpture. }\end{array}$ & $\begin{array}{l}\text { Human validation e.g. family } \\
\text { reconstruction, family plan, ice mount } \\
\text { metaphor and contrastive positions, } \\
\text { bringing the past of members to the } \\
\text { present i.e. each member knows about } \\
\text { their communication patterns and } \\
\text { the role of childhood and the effect of } \\
\text { interactions by reconstructing the past. }\end{array}$ & $\begin{array}{l}\text { Describing and } \\
\text { recording occurred } \\
\text { events, determining and } \\
\text { recording the kind of } \\
\text { reactions to them. }\end{array}$ \\
\hline 3 & $\begin{array}{l}\text { Self-worth and self } \\
\text { esteem }\end{array}$ & $\begin{array}{l}\text { awareness } \\
\text { facilitation about } \\
\text { the present }\end{array}$ & $\begin{array}{l}\text { Checking previous assignments, investigating } \\
\text { family members' validation, defining self-growth } \\
\text { with the help of family members, sharing } \\
\text { members' experiences }\end{array}$ & $\begin{array}{l}\text { Making hope in family members by } \\
\text { the use of therapeutic techniques, } \\
\text { making access to internal facilities } \\
\text { and sources, giving opportunities } \\
\text { to family members to express } \\
\text { their feelings easily, helping family } \\
\text { members to reframe, know their } \\
\text { values and validate them. Behavinn } \\
\text { on the basis of self-worth, i.e. } \\
\text { members behave based on the } \\
\text { values they define for themselves. }\end{array}$ & $\begin{array}{l}\text { Describing and } \\
\text { recording occurred } \\
\text { events, determining and } \\
\text { recording the kind of } \\
\text { reactions to them. }\end{array}$ \\
\hline 4 & $\begin{array}{l}\text { Internal abilities and } \\
\text { sources for change } \\
\text { and reaching to } \\
\text { growth perfection }\end{array}$ & $\begin{array}{l}\text { Unifying visions } \\
\text { and awareness of } \\
\text { past and present }\end{array}$ & $\begin{array}{l}\text { Checking previous assignments, investigating } \\
\text { factors affecting human change and growth, } \\
\text { investigating potential abilities and internal } \\
\text { capabilities to change in each family member, } \\
\text { investigating the elements of floating ice mass in } \\
\text { each family member. }\end{array}$ & $\begin{array}{l}\text { Using therapeutic techniques } \\
\text { related to human validation pattern } \\
\text { e.g. organs party and ice mount } \\
\text { metaphor in order to coordinate family } \\
\text { members, also unifying visions and } \\
\text { awareness of past and present }\end{array}$ & $\begin{array}{l}\text { Describing occurred } \\
\text { events, determining } \\
\text { and recording internal } \\
\text { sources and potential } \\
\text { abilities }\end{array}$ \\
\hline 5 & $\begin{array}{l}\text { New choices, } \\
\text { learning new } \\
\text { behaviors and using } \\
\text { them (coordinated } \\
\text { message delivery } \\
\text { style) }\end{array}$ & $\begin{array}{l}\text { Determining } \\
\text { targets for change, } \\
\text { planning to } \\
\text { change }\end{array}$ & $\begin{array}{l}\text { Checking previous assignments, investigating } \\
\text { each member's role in family and its effect } \\
\text { on family operation, determining inconsistent } \\
\text { patterns with the help and cooperation of } \\
\text { family members, reaching to a consistent } \\
\text { communication pattern among family members. }\end{array}$ & $\begin{array}{l}\text { Using reframing techniques, kidding, } \\
\text { ropes, using I phrase in order to } \\
\text { remove inconsistent communication } \\
\text { patterns and reaching to consistent } \\
\text { communication patterns in family. }\end{array}$ & $\begin{array}{l}\text { Recording occurred } \\
\text { occasions in which } \\
\text { inconsistent patterns are } \\
\text { replaced with consistent } \\
\text { ones. Recording those } \\
\text { occasions which were } \\
\text { unsuccessful in that } \\
\text { replacement. }\end{array}$ \\
\hline 6 & $\begin{array}{l}\text { Showing different } \\
\text { and new behaviors } \\
\text { compared to old } \\
\text { ones }\end{array}$ & $\begin{array}{l}\text { Working on } \\
\text { changes and } \\
\text { recording them }\end{array}$ & $\begin{array}{l}\text { Checking previous assignments, working } \\
\text { on desired changes in therapeutic session, } \\
\text { appearing new behaviors in therapeutic session } \\
\text { and recording the changes }\end{array}$ & $\begin{array}{l}\text { Giving assignments, using changes } \\
\text { in therapeutic sessions e.g. feelings } \\
\text { and expectations observation, } \\
\text { manifesting perceptions and beliefs, } \\
\text { communication making with desires } \\
\text { and wishes, and getting aware of } \\
\text { interactions among elements }\end{array}$ & $\begin{array}{l}\text { Giving assignment } \\
\text { in order to keep the } \\
\text { recorded changes in } \\
\text { therapeutic sessions }\end{array}$ \\
\hline 7 & $\begin{array}{l}\text { Showing different } \\
\text { and new behaviors } \\
\text { compared to old } \\
\text { ones }\end{array}$ & $\begin{array}{l}\text { Working on } \\
\text { changes and } \\
\text { recording them }\end{array}$ & $\begin{array}{l}\text { Checking previous assignments, working } \\
\text { on desired changes in therapeutic session, } \\
\text { appearing new behaviors in therapeutic session } \\
\text { and recording the changes }\end{array}$ & $\begin{array}{l}\text { Giving assignments, using changes } \\
\text { in therapeutic sessions e.g. feelings } \\
\text { and expectations observation, } \\
\text { manifesting perceptions and beliefs, } \\
\text { communication making with desires } \\
\text { and wishes, and getting aware of } \\
\text { interactions among elements }\end{array}$ & $\begin{array}{l}\text { Giving assignment } \\
\text { in order to keep the } \\
\text { recorded changes in } \\
\text { therapeutic sessions }\end{array}$ \\
\hline 8 & $\begin{array}{l}\text { Integration and } \\
\text { unification, the } \\
\text { end of therapeutic- } \\
\text { instructional } \\
\text { sessions }\end{array}$ & $\begin{array}{l}\text { Performing new } \\
\text { behaviors out } \\
\text { of therapeutic } \\
\text { sessions and in } \\
\text { natural occasions }\end{array}$ & $\begin{array}{l}\text { Investigating a summary of previous sessions } \\
\text { and evaluating the results of instructional } \\
\text { sessions }\end{array}$ & & \\
\hline
\end{tabular}

Table 1: The summary of training sessions based on the pattern of human validation process. 
Citation: Ebrahimi L (2018) The Effectiveness of Human Validation Process Model Training on Couples' Marital Satisfaction. J Ment Disord Treat 4 155. doi:10.4172/2471-271X.1000155

Page 4 of 5

\begin{tabular}{|c|c|c|c|c|c|c|}
\hline Groupes Indices & Sample size & $\begin{array}{c}\text { The average of } \\
\text { differences }\end{array}$ & Standard deviation & Standard error & $\mathbf{T}$ & Significance level \\
\hline Experimental & 26 & 8.31 & 4.23 & 0.82 & \multirow[t]{2}{*}{8.81} & \multirow[t]{2}{*}{0.001} \\
\hline Control & 26 & 0.73 & 1.28 & 025 & & \\
\hline
\end{tabular}

Table 2: A comparison between marital scores in pre-test and post-test in experimental and control groups.

\begin{tabular}{|l|c|c|c|c|c|}
\hline Groupes & Indices & Sample size & $\begin{array}{c}\text { Average of } \\
\text { differences }\end{array}$ & Standard deviation & Standard error \\
\hline women & 13 & 10.46 & 4.14 & 1.15 \\
\hline Men & 13 & 6.63 & 3.46 & 0.96 \\
\hline
\end{tabular}

Table 3: The average of score differences in pre-test and post-test of marital satisfaction in after holding sessions.

the mean of pre-test scores was calculated as 98.73 , standard deviation as 20.5 and standard error as 4.02)showed that there was no difference between the two control and experimental groups before training based on human validation pattern and the averages of their pre-test, standard deviation and standard error were almost the same (Table 2).

According to the obtained values, since the calculated $\mathrm{T}$ for independent groups (8.81) was bigger than the its critical value with $\mathrm{df}=50$ (1.67), the null hypothesis claiming there was a lack of difference between pre-rest and post-test scores is rejected and the alternative hypothesis predicating the effect of using independent variable (training based on the pattern of human validation process) on dependant variable (marital satisfaction) is confirmed. Hence, it can be said that training based on the pattern of human validation process in experimental group will induce significant differences in post-test results of experimental group (Table 3 ).

Identifying the effect of training based on the pattern of human validation process in men and women The average of score differences in pre-test and post-test of marital satisfaction in after holding sessions for men and women in experimental group with regard to table results, since the $\mathrm{T}$ value calculated for correlated groups (repeated measurements for the same group) (9.09) was greater than its critical one with $\mathrm{df}=12$ and $\alpha=0.05$ (2.17), the null hypothesis predicting lack of difference between men's and women's score in post-test is rejected and the alternative hypothesis claiming upon the difference between the effectiveness of independent variable (training based on the pattern of human validation process) and dependent variable (marital satisfaction) on men and women is confirmed. Therefore, the results showed that while the training was useful in both groups, it was more effective in women. In other words, the training based on the pattern of human validation process has been most effective in women.

\section{Discussion and Conclusion}

The present study aimed to investigate the effectiveness of the training based on the pattern of human validation process on marital satisfaction enhancement. In the pattern of human validation process, family conflicts and problems stem from communication disorders which in turn stem from low self-esteem and self-worth of family members. Therefore, the present pattern is directed toward increasing self-worth and self-esteem of family members and improving their communication relationships and styles. Hence, teaching this pattern would be greatly effective in increasing marital satisfaction.

A brief look at results of the study shows that those who referred to counseling centers with family problems, though within a wide age range (from 17 to 41 ) and within a limited marriage length (from few months to 8 years), the most frequent problems existed within the first three years of marriage life (about 70\%). This means that, divorce risk is quiet higher in those years. This is also consistent with a research conducted by Noorbala [23].

Since the pattern of human validation process takes advantage of a wide range of therapeutic methods and techniques, it can serve as a comprehensive method for treating family problems with regard to the country culture. In the present study, the effectiveness of the pattern has been confirmed by inducing positive changes in the post-test conducted on experimental group. The results of the present study showed that holding training sessions based on this pattern could resolve the problems regarding family members' relationships, their self-esteem and their self-worth and could strengthen the desired elements of the study. In fact, the ability to communicate, enhance self-esteem and self-worth, express feelings, coordinate verbal and nonverbal messages, increase the awareness about "self" elements as well as ice mount metaphor elements, and also, enhance the potency of individuals to change into a perfect human and to augment responsibility, would all lead to the increase of marital satisfaction within families [24].

\section{References}

1. Nazari A (2004) Investigating and Comparing the Effect of Communication Enriching Program and Solution-Based Counseling on Marital Satisfaction of Working Couples.Teacher Training University.

2. Ellis A (1989) Rational emotive couples therapy New York: pergamon press

3. Morris ML, Carter SA (2000) Transition to marriage: A Literature Review. JFCSE.

4. Mollania SH (2003) Couples' Maladjustments, Reasons and Factors, A Field Study inn Sari Province. Unpublished Master's Dissertation, Tehran Institute of Psychiatry.

5. Sharoff R (1996) Theories of Psychotherapy and Counseling Tehran: Rasa Press.

6. Moradi M (2000) Investigating the Effect of Martial Relationship Training on Marital Satisfaction. Unpublished Master's Desertation A-Zahra University.

7. Stack S, Eshleman JR (1998) Marital status and happiness: A 17nation study Journal of Marriage and the family 60: 527-536.

8. Laub JH, Nagin DS, Sampson RJ (1998) Trajectories of change in review, criminical offending: Good marriages and the distance process. American Sociological 63: 225-238.

9. Baucom DH, Shoham DH, Mueser KT, Daiuto AD, Sticklet TR (1998) Empirically supported couple and family intervention. Journal of Consulting and Clinical Psychology 66: 53-88.

10. Carr A (2000) Family Therapy (the Concepts of Processes and Practices for Couple Therapy.

11. Gladding S (1995) Family Therapy, History, Theory and Practice. Bahari F (ed.) Tehran: TazkiehPress.

12. Parsons BV, Alexander JF (1973) Short-term family intervention: A Therapy outcome study: Journal of Counseling and Clinical Psychology 41: 195-207.

13. Christensen A, Shenk JL (1991) Communication, Conflict, and psychologica 
Citation: Ebrahimi L (2018) The Effectiveness of Human Validation Process Model Training on Couples' Marital Satisfaction. J Ment Disord Treat 4: 155. doi:10.4172/2471-271X.1000155

Page 5 of 5

distance in non distressed, clinic, and divorcing couples. Journal of consulting and clinical psychology 59: 458-463.

14. Kaiser A, Hahlweg K, Wolfsdorf GF, Groth T (1998) The eficacy of a compact psychoeducational group training program for married couples. Journal of consulting and clinical psychology 66: 753-760.

15. Pan PJD (2000) The Effectiveness of structured and semi structured Satir model Groups on Family Relationship with college student in Tawan. Journal for specialists in group work 23: 305-318.

16. Dadash Z, Sanai B, Alimohammadi M (2007) The Effect of Family Reconstruction on the Quality of Mother-Daughter Relationship. Journal of Counseling Research and Developments.

17. Olson DH, Fournier DG, Druckman JM (1989) Families. California: Sage Publication Inc.

18. Wadsby M (1998) Evaluation of the Swedish Version of the ENRICH Marital Inventory. Nordic Journal of Psychiatry 52: 379-387.
19. Soleimanian A (1994) Investigating the Effect of Irrational thinking on Marital Satisfaction of Student Teachers.

20. Rasooli A (2004) Investigating the Relationship Between Mental Health, Marita Satisfaction and Educational Performance of Male and Female BA students of Islamic Azad University of Kermanshah. Unpublishe Master's Dissertation. Tehran: Islamic Azad University, Science and Research Branch.

21. Sanaei B (2000) Measurement Scales of S family and Sarriage. Tehran: Be'sat press.

22. Behpazhooh A, Ramazani F (2004) Investigating Marital Satisfaction among the Parents of Mentally Handicapped Children and Non-handicapped Children. Journal of Social Sciences and Humanities of Shiraz University.

23. Noorbala A, Ameri F, Ejei J, Rsoulzadeh K (2003) Investigating the Confirmation of Strategic Family Therapy Observation in Marital Problems. Journal of Psychology.

24. Fowers BJ, Olson DH (1989) Enrich Marital Inventory: A Discriminant Validity and Cross-Validity Assessment. Journal of Marital \& Family Therapy 15: 65-79. 